\title{
Managing the Implementation of a School Curriculum in Malawi: Challenges and Policy Implications
}

\author{
Article by Byson Colyns Sabola \\ Training Officer, African Regional Intellectual Property Organization (ARIPO), Zimbabwe \\ Email: bsabola3@gmail.com
}

\begin{abstract}
The study was conducted to investigate how the implementation of the Malawi senior secondary school revised curriculum was managed by exploring the underlying factors behind the students' poor academic performance in Social and Development Studies (SDS) national examinations. To accomplish this purpose, the study examined the challenges faced by teachers in their teaching of SDS and assessed the effectiveness of the supervisory and advisory support provided to teaches by heads of department and head teachers. The study further explored the policy implications of the experienced challenges for curriculum implementation. The study took a qualitative approach and used face-to-face interviews to collect data from teachers, Heads of Department and Head teachers in eight secondary schools in South Eastern Education Division. The findings revealed that the implementation of SDS faced a number of challenges such as lack of teaching and learning materials including textbooks, lack of trained teachers, and lack of in-service training for the practising teachers who were assigned to teach the subject. In addition, teachers were not given adequate supervisory and advisory support by heads of departments, head teachers and school inspectors. The study concluded that the introduction of the revised senior secondary school curriculum was poorly managed such that the schools did not have adequate capacity to successfully implement the teaching of newly introduced subjects like SDS. The study recommends that the Ministry of Education should ensure that, in future, implementation of a new curriculum is adequately planned for in terms of availability of instructional materials, specialised teachers and in-service training for teachers as well as provision of adequate teacher supervisory and advisory support by heads of department, head teachers and school inspectors.
\end{abstract}

Keywords: curriculum implementation, teacher factors, continued professional development, instructional materials, specialist teachers, in-service training.

\section{Introduction}

In Malawi, the curriculum is operational for a period of ten years after which a review can take place to ensure that it is up-to-date (Government of Malawi, 2002). A curriculum is reviewed in response to societal needs of a particular time and context (Kurasha \& Chabaya, 2013). A curriculum can also be reviewed to improve the quality of education (Nyirenda, 2005). In Malawi, the secondary school curriculum was reviewed to make it more responsive to the social, economic and developmental needs by incorporating contemporary critical issues such as HIV and AIDS, population explosion, environmental degradation, gender issues and human rights education.

When the Ministry of Education revised the secondary school curriculum, new subjects were introduced in the curriculum, new content was added in some subjects and new approaches to teaching and learning were incorporated. Social and Development Studies (SDS) was one of the new subjects which were introduced in the senior secondary school curriculum. However, poor performance of students in national examinations had been the concern of the nation. SDS had been one of the most poorly performed subjects in national examinations. This signalled that the implementation of SDS in secondary schools was facing problems. 
DOI: $10.21522 /$ TIJMG.2015.03.02.Art011

ISSN: $2520-310 \mathrm{X}$

\section{Purpose and objectives of the study}

The purpose of the study was to investigate how the implementation of the Malawi senior secondary school revised curriculum was managed by exploring the underlying factors behind the students' poor academic performance in SDS. To accomplish this purpose, the study focused on achieving the following objectives:

1. To investigate the challenges faced by teachers in their teaching of SDS.

2. To assess the effectiveness of the supervisory and advisory support services provided to teachers by heads of department, head teachers and inspectors of schools.

3. To explore the policy implications of the experienced challenges on curriculum implementation.

The study was significant in providing empirical insights and valuable information to curriculum policy makers, curriculum developers and implementers, on the challenges that teachers, heads of department, head teachers and inspectors of schools encounter in implementing new curriculum innovations. The findings could also act as a basis for policy debate and dialogue amongst educationists, academics, curriculum developers, and teacher trainers on how the capacity of schools can be strengthened to effectively implement school curriculum. The findings may stimulate further research on curriculum implementation challenges faced in other subjects or disciplines of study.

\section{Literature review}

\section{The concept of curriculum implementation}

Various authors understand the concept of curriculum implementation differently. Fullan (2001) describes implementation as consisting of the process of putting into practice an idea, program or set of activities and structures new to the people attempting or expected to change. On the other hand, Ndawi (1994), Posner (1995), and Zanzali (2003) define curriculum implementation depending on which model of curriculum development was used. They argue that in the Centre-Periphery Models, where the curriculum is planned and developed elsewhere and then handed down to teachers for use, curriculum implementation is defined as the transformation of the aspirations of the curriculum developers into a form that can be understood by the pupils. In the Collaborative Model, also known as Concentric Circle approach or Cooperative Model of curriculum development, the curriculum implementers (the teachers) are actively involved, such that curriculum implementation just means the teachers taking the curriculum they participated in its development for use in the classroom. The curriculum developers and implementers (teachers) collectively determine the decisions they take in curriculum implementation both in planning and execution. In this model, the teachers' views are important and relevant and play a role commensurate with the pivotal position that teachers occupy within the education system (Aubusson \& Watson, 1999). Glickman (1990) highlights the point that it makes no difference how good a curriculum is if teachers will not use it. Glatthorn (1994) further describes curriculum implementation as including the provision of organised assistance to teachers to ensure that the newly developed curriculum and instructional strategies are delivered effectively at the classroom level. Although these different authors describe curriculum implementation from different perspectives, they all agree that it is at the classroom level where implementation of a curriculum takes place.

\section{Challenges to curriculum implementation}

A lot of factors that act as obstacles to implementation of a new curriculum have been identified in literature. Bennie \& Newstead (1999) pointed out that the factors relate to the teacher as well as the context in which the curriculum is being implemented. Some of the challenges to implementation of a new curriculum as given in the literature include the following:

\section{Knowledge of subject matter}

In their discussion of professional development and reform in Science Education in Netherlands, Van 
Driel et al (2001) have pointed out teachers' lack of adequate knowledge of the new content as one of the problems that can arise during implementation of a new curriculum. Other studies on curriculum implementation by Bennett et al (1992), Wallace \& Louden (1992), Raudenbush et al (1993), and FraserThomas \& Beaudoin (2002), revealed that low levels of teachers' knowledge of the subject matter was an obstacle to the successful delivery of a curriculum at the classroom level. A study by Benavot \& Resh (2003) to investigate factors that influenced curriculum implementation in Israeli schools found that successful implementation of a curriculum in schools depended on school-based conditions and constraints which included the availability of specialised teachers in particular subjects.

\section{Availability of teaching and learning materials}

Benavot \& Resh (2003) found that successful implementation of a curriculum in Israel also depended on the amount of instructional resources at a school's disposal. Similar findings were revealed in separate studies by Nyirenda (1994), Hart (1994), Fraser-Thomas \& Beaudoin (2002), and Graham-Jolly (2003) who highlighted lack or inadequacy of teaching and learning materials as a major challenge to curriculum implementation. Concerning the importance of textbooks during curriculum implementation, Lockheed et al (1986), argued that textbooks provide teachers with a more structured and comprehensive presentation of the subject matter than would otherwise be available to them. In the absence of inadequacy of textbooks, the teacher becomes the custodian of knowledge and skills for most students that take national examinations in Malawi (Chakwera, 2005).

\section{In-service training}

Lack of in-service training has also been reported in literature as one of the challenges to curriculum implementation. In a study of teachers' beliefs about the meaning and relevance of problem solving in the Mathematics curriculum in Malaysia, Zanzali (2003) observed that development and implementation of any curriculum affect teachers in significant ways and if teachers are not helped in coping with demands brought about by changes in the content, pedagogical and psychological considerations, the implementation process will not be effective. After evaluating curriculum implementation in South Africa, Graham-Jolly (2003) reports that at school level, implementation highlighted critical factors which pointed to the underpreparedness of many teachers and schools to accommodate the curriculum change. Concerning the implementation of the same South African curriculum, Jansen (2003) reports that the curriculum was being introduced into an under-prepared environment in which the prerequisite teacher training and curriculum awareness were not in place. According to Middleton (1999), the most difficult challenge which faces the implementation of a curriculum is the training and preparation of the existing teachers who will be needed to make the curriculum a classroom reality. These observations indicate that curriculum orientation for existing teachers before they embark on its implementation is very important to make them understand and appreciate the changes that the curriculum is attempting to incorporate, thereby preparing them to handle those curriculum changes. Commenting on the importance of in-service training before introduction of any curriculum, little (1993) emphasises that professional development prepares teachers for implementation by placing classroom practice in the larger contexts of school practice and the educational career of children. Ogar and Aniefiok (2012) in their discussion of the challenges of implementing a teacher education

curriculum in Nigeria, hinted on the importance of adequate teacher training because the success of curriculum implementation is dependent on the teachers' ability to translate the written curriculum into classroom learning experiences.

\section{Provision of teacher support services}

Lack of supervisory support for teachers' acts as a challenge to the effective implementation of any curriculum (Glickman, 1990). The importance of supervising teachers has been described by Raudenbush et al (1993) who argue that "observation followed by immediate and skilled feedback on classroom instruction provides a basis for teacher learning with direct relevance to teaching" (p. 280). Raudenbush et 
DOI: $10.21522 /$ TIJMG.2015.03.02.Art011

ISSN: $2520-310 \mathrm{X}$

al (1993) further report that in Thailand, principals (head teachers) are expected to provide each teacher with regular classroom supervision either by visiting classrooms personally or by assigning expert teachers to do so. In Malawi, heads of department, head teachers and inspectors of schools are supposed to provide teacher support services by conducting regular classroom supervision.

\section{Theoretical framework}

This study was guided by the theoretical framework illustrated in Figure 1. This framework is an adaptation of the one developed by Rogan \& Aldous (2005) which is based on the theory of curriculum implementation developed by Rogan \& Grayson (2003). The theory consists of profile of implementation, capacity to support innovation and support from outside agencies as its three major constructs. Discussion of these three constructs is done in the sections that follow.

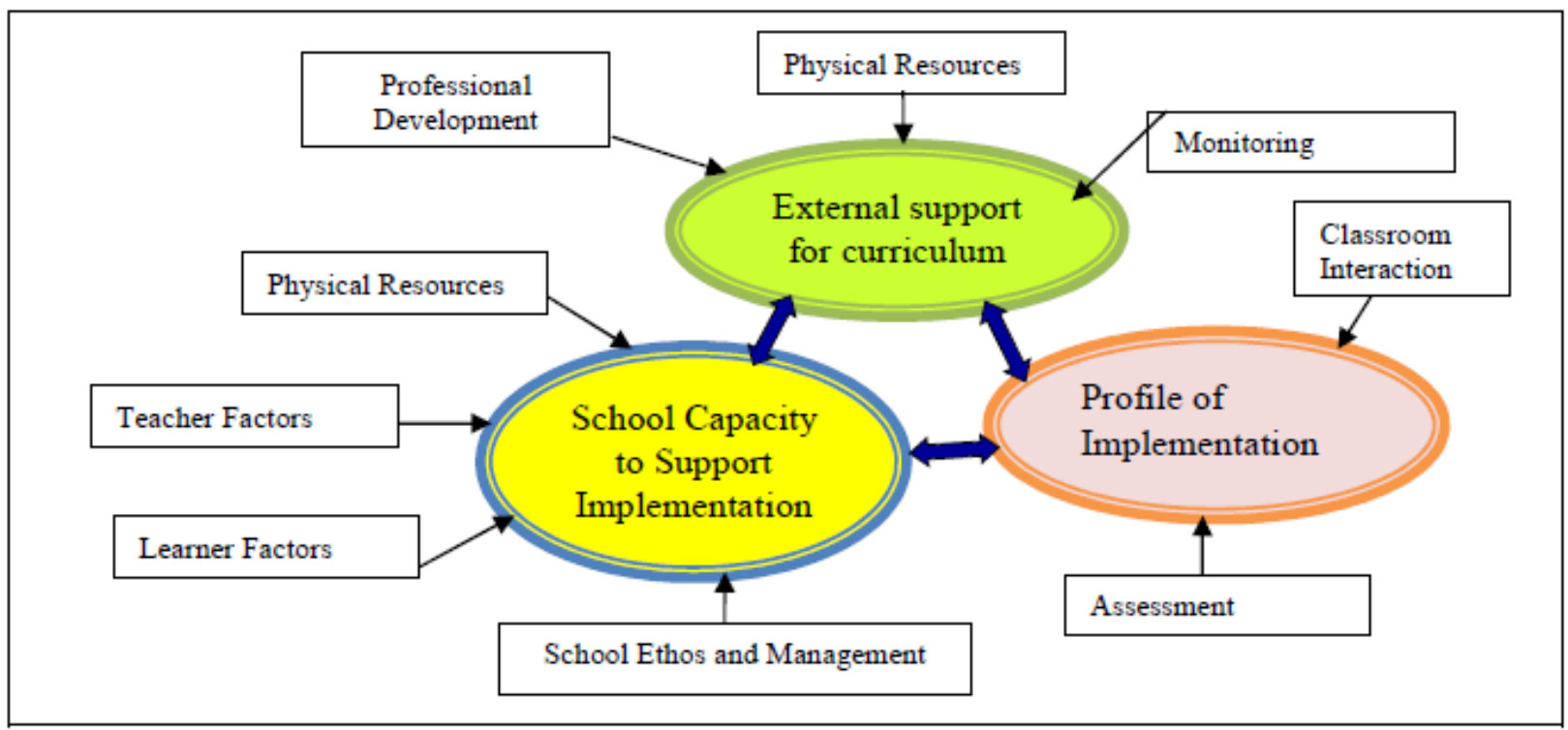

Figure 1. Theoretical framework for curriculum implementation (adapted from Rogan \& Aldous, 2005)

\section{Profile of implementation}

This is a construct that helps to understand, analyse and express the extent to which the ideals of a set of curriculum proposals are put into practice. This construct recognises that there are as many ways of putting a curriculum into practice as there are teachers teaching it. Therefore, the profile of implementation offers a map of the learning area and a number of ways for implementation. The profile can also help to conceptualise levels of implementation of a new curriculum.

\section{School capacity to support curriculum implementation}

The construct (capacity to support curriculum implementation) is an attempt to understand and elaborate on the school-based factors that support or hinder the implementation of new curriculum ideas and practices. Schools differ from one another and therefore not all schools have the same capacity to implement a curriculum innovation to the same extent. In the framework, possible indicators of the capacity to support implementation construct fall into four groups. These are physical resources, teacher factors, learner factors and the school ethos and management.

Physical resources also influence the capacity for curriculum implementation. Poor resources, unavailability of resources or inadequate resources can limit the performance of even the best of the teachers and can undermine learners' efforts to focus on learning. Teacher factors include teachers' own background, training and level of confidence, and their commitment to teaching. Because teachers 
implement a curriculum on a day-to-day basis, they play an enormous role in the effective implementation of curricula. Lack of subject matter knowledge by teachers and lack of adequate training for teachers could be a major hindrance to curriculum implementation. Learner factors relate to the background of the learners and the kind of strengths and constraints that they might bring to the learning situation. For example, the home environment may not be educationally supportive or the learner may not be proficient in the language of instruction.

The next set of factors pertains to the general ecology and management of the school. If a school is in disarray and dysfunctional, it is obvious that no innovation can be effectively implemented. In such cases, the first step in implementing an innovation would be to restore order and discipline. Those charged with the implementation of curriculum change need to be supported in a variety of ways. Therefore the leadership role of the Head teacher is crucial for curriculum implementation.

\section{External support for curriculum implementation}

According to the theoretical framework in Figure 1, outside agencies or organisations external to the school interact with a school in order to facilitate curriculum implementation. These organisations could be government departments, donors (both local and international), NGOs and unions. In this study, external support focused on provision of professional development and monitoring of curriculum implementation.

\section{Methodology}

\section{Research design and sampling technique}

The study took a qualitative approach and used face-to-face interviews to collect data from purposively sampled teachers, heads of department responsible for SDS and head teachers in eight secondary schools and school inspector in the South Eastern Education Division (SEED). The participants were purposively sampled because they played different roles during implementation of SDS when it was just introduced in the curriculum. The heads of department and head teachers were charged with the responsibility of carrying out school-based supervision of teachers to provide advisory support. The head teachers were also overseers of every activity that took place in the school including curriculum implementation. A total of 25 participants were interviewed and consisted of one teacher, one head of department responsible for SDS and the Headteacher from each of the eight schools and the inspector of schools who was based at the South Eastern Education Division Office.

\section{Data collection instruments and procedure}

Two interview guides were used during the study. One guide was used with classroom teachers of SDS to identify the challenges they faced in their teaching of SDS. The other interview guide was used with heads of department, head teachers and school inspector to assess the effectiveness of the supervisory and advisory support they provided to teachers during the implementation of SDS. Both interview guides consisted of open-ended questions to allow respondents to freely express their views and ideas. Face-to-face interviews were used to collect in-depth information through probing as well as to accord the researcher an opportunity to clarify questions where they were not understood, thereby increasing the likelihood of getting useful responses. During the interview sessions, the researcher wrote down the responses to the questions. In addition, the interview sessions were tape-recorded after getting consent from individual respondents. Tape-recording helped to reduce the amount of time taken for each interview session. However, not all teachers accepted to be tape-recorded. Where a participant was not comfortable to be taperecorded, responses were just written down by the researcher.

\section{Data analysis}

Analysis of qualitative data began as soon as data collection commenced and it continued after data collection. This was helpful because the memories of the interviews were still fresh in the mind. Taperecorded interview sessions were transcribed and typed. The analysis focused on how individuals 
DOI: $10.21522 /$ TIJMG.2015.03.02.Art011

ISSN: $2520-310 \mathrm{X}$

responded to each question. Therefore, all the data for each question were put together. After organising the data by question, themes were identified and then organised into coherent categories.

\section{Results and discussion}

The study investigated how the revised curriculum was managed to result in poor performance of students in some subject areas in national examinations. According to the theoretical framework in figure 1 , the study focused on factors that relate to school capacity to support curriculum implementation and external support for curriculum implementation. The study revealed that the following challenges were experienced in the teaching of SDS:

\section{Challenges related to school capacity to support curriculum implementation}

\section{Lack of specialist teachers for the subject}

The study revealed that lack of specialist teachers for SDS was a factor that negatively affected the capacity of schools to support the implementation of SDS. Implementation of SDS started when there were no specialised teachers for the subject. As a result, teachers lacked confidence in their teaching due to possession of inadequate knowledge of the subject matter. In three out of eight sampled schools, the head teachers reported that, at its introduction in the curriculum, SDS was taught by teachers who were underqualified to teach at secondary school level. These teachers had Primary School Teacher's Certificate (PSTC), a primary school teachers' qualification but were teaching in secondary schools due to shortage of qualified secondary school teachers. This status undermined their ability and confidence to teach the subject effectively thereby weakening the schools' capacity to support implementation of the revised curriculum. Similar findings were reported by Ongachi, Okello and James (2013) in their study of the challenges affecting implementation of Art and Design Curriculum in Kenyan secondary schools. It was reported that "there were teachers in secondary schools system who taught Art and Design Curriculum yet they were not trained to teach in secondary schools" (p. 392). Syomwene (2013) also alluded to the lack of trained teachers as one of the impeding factors to implementation of curriculum reforms and educational policies in schools in Kenya.

This study has confirmed the findings of a similar study by Wallace \& Louden (1992) which revealed that science teachers with higher level of knowledge taught more confidently than those with lower knowledge levels. It is therefore important that a teacher should possess a rich knowledge base of content and pedagogy to provide relevant and meaningful learning experiences for pupils (Medrano \& Curts, 2004). The importance of teachers' mastery of the subject content was also alluded to by Urbanski (2004) who argued that even if the best materials are given to a teacher, those materials will not be used effectively for pupils' learning if that teacher lacks subject knowledge. Urbanski further pointed out that priority should be given to having knowledgeable teachers who are capable of translating the curriculum into classroom experiences for effective student learning. Otherwise inadequate mastery of subject matter by teachers affects students learning which subsequently leads to poor performance in the affected subject areas.

\section{Inadequate teaching and learning resources}

The theoretical framework as given in Figure 1 gives availability of resources as one of the factors that can support the implementation of a curriculum and textbooks are one of such teaching and learning resources. Textbooks facilitate teaching and learning (Kuthemba Mwale, 2000) in that teachers can give reading assignments to pupils when textbooks are available. Teachers cannot teach the pupils everything and therefore reading the textbooks also helps to widen the pupils' knowledge base and promote active participation of pupils in lessons. In all the eight sampled schools, shortage of teaching and learning resources including textbooks was cited as one of the biggest challenges that teachers were facing in their teaching of SDS. Lack of teaching and learning resources as a challenge to curriculum 
implementation was also reported in Nigeria (Njoku and Njoku, 2015), in Zimbabwe (Dzimiri and Marimo, 2015) and in Tanzania (Makunja, 2016).

\section{Inadequate capacity of school management to supervise curriculum implementation}

In Malawi, school level monitoring of curriculum implementation is the responsibility of head teachers and heads of departments. One way of monitoring curriculum implementation is through regular supervision of teachers in their teaching. The study revealed that head teachers and heads of departments did not adequately supervise the implementation of SDS in their respective schools. Inadequate supervision of implementation of SDS was a school management problem that weakened the capacity of schools to effectively implement the approved curriculum. This revelation confirms the results of a study by Syomene (2013) which reported that inefficient school leadership and management failed to provide adequate supervision of classroom teaching to ensure effective curriculum implementation in Kenyan schools. Similar findings were also reported by Shilling (2013) in a study that examined the opportunities and challenges of curriculum mapping implementation in a school setting.

\section{External support for curriculum implementation}

\section{In-service training}

In-service training helps to prepare teachers for curriculum implementation (Rogan \& Aldous, 2005). The Ministry of Education (2000) stated that the central focus of any curriculum reform is teacher preparation and therefore in-service education and training programmes are one of the primary routes for introducing and sustaining educational change at school level. However, although SDS was being implemented by non-specialist teachers, all the eight teachers who participated in the study reported that lack of orientation and in-service training for the existing practising teachers of SDS had contributed to ineffectiveness in their teaching of the subject. These findings also confirm the results of a study that was conducted to investigate the challenges teachers faced in implementing competence-based curriculum in Tanzania (Makunja, 2016). It was reported that lack of in-service training for teachers was a major challenge that affected the successful implementation of competence-based curriculum. A similar revelation was reported by Njoku \& Njoku (2015) who investigated challenges to effective implementation of Christian Religious Studies Curriculum in Nigeria. They reported that teachers who were not exposed to in-service training seminars and workshops were not abreast with current trends in teaching approaches and could not use instructional materials and understand new content required for effective implementation of a curriculum. Okoth (2016) also reported that lack of Teacher Professional Development initiatives negatively affected school level curriculum implementation efforts. Mtetwa (2003) alluded to this by contending that if pre-operational processes such as orientation and training of teachers, have not taken place, curriculum implementation experiences some problems. Zanzali (2003) pointed out that in-service training of teachers helps teachers to cope with demands brought about by changes in curriculum content. A study by Jones, Harlow \& Cowie (2004) of New Zealand teachers' experiences in implementing Technology Curriculum also revealed the importance of in-service training in preparing teachers for implementation. Therefore, in-service training could have provided teachers of SDS with the necessary knowledge and skills for the teaching of the subject. In addition, in-service training could have helped to introduce new concepts and approaches to the teaching of SDS.

\section{Inadequate monitoring of curriculum implementation by school inspectors}

It is important to note that monitoring curriculum implementation through regular supervision and provision of advisory services help to promote professional growth of teachers. Such services provide support to teachers by promoting good pedagogical practices, check and discourage unprofessional practices, and provide teachers with relevant information for their professional development. However, 
DOI: $10.21522 /$ TIJMG.2015.03.02.Art011

ISSN: $2520-310 \mathrm{X}$

the study revealed that teachers were not provided with the advisory support in their teaching of SDS. Of the teachers who were interviewed during the study, $63 \%$ indicated that school inspectors rarely visited the schools to monitor curriculum implementation and provide advisory services. The teachers reported that advisory services were essential during the implementation phase of SDS as a new subject in the curriculum especially because some of the teachers were primary school teachers who needed more assistance to teach the subject. The inspector of schools corroborated with the teachers' observation by stating that failure to supervise teachers of SDS was not deliberate. It was reported that besides lack of adequate funding, supervision and inspection visits to schools were made without knowing what subjects were timetabled for that day. This was being done following the Ministry of Education's (1982) policy guideline on inspection and supervision which required the inspector, upon arrival at a school, to get the day's timetable from the head teachers' office to decide which teachers, lessons and classes to supervise. Therefore, only those teachers of the subjects timetabled for that day would be supervised. This approach had left the teaching of SDS, as a new subject in the curriculum, inadequately targeted for supervision. Some of the problems that teachers of SDS had been experiencing could have been attended to if the teaching of the subject was adequately supervised. Bekoe \& Eshun (2013) pointed out that, as a way of improving the education system or ensuring its effectiveness, curriculum design and its implementation need to be adequately monitored. Use of under-qualified teachers, lack of specialist teachers and lack of orientation for teachers should have called for more attention to be given to teachers of SDS, in terms of supervision and advisory services. Therefore, lack of adequate funding for supervision of teachers, especially at the implementation stage, meant that there was inadequate planning for the implementation of SDS on the part of the Ministry of Education.

\section{Effectiveness of support services provided to teachers by heads of department, head teachers and inspector of schools}

The second objective of the study was to assess the effectiveness of the supervisory and advisory support services that heads of department, head teachers and inspectors of schools provided to teachers. During the study, heads of department and head teachers reported that they did not provide adequate and effective support services to teachers due to inadequate subject knowledge, lack of supervision skills, and teachers' resistance to supervision.

\section{Inadequate subject knowledge}

Lack of adequate knowledge in the subject was cited by $63 \%$ of the heads of department and $75 \%$ of the head teachers. They argued that it was difficult to supervise teachers on the subject they themselves did not specialise in. This implied that the heads of department and head teachers lacked confidence to supervise and provide advisory services for the teaching of SDS in which they did not have adequate knowledge.

\section{Lack of supervision skills}

The Ministry of Education (2001) in its Policy and Investment Framework (PIF) states that the Ministry of Education would continue to take appropriate measures aimed at strengthening the professional competence of secondary head teachers and heads of department to carry out methods and advisory services within the schools. While one of the methods and advisory services is the supervision of teachers in their teaching, the study revealed that the Ministry of Education did not equip the head teachers and heads of department with the necessary classroom supervision skills. Lack of classroom supervision skills was cited by $50 \%$ of the head teachers and by $75 \%$ of the heads of department.

According to the curriculum implementation theoretical framework in Figure 1, lack of supervision skills is a management factor that weakened the schools' capacity to support the teaching of SDS. This entailed that the Ministry of Education did not implement its plans of strengthening the professional competence of heads of department and head teachers as stated in the PIF. In the end, the victim is the 
student whose learning and therefore performance in both school and national examinations gets negatively affected.

\section{Resistance to supervision}

Raudenbush et al (1993) define supervision as referring to the activities of those invested with administrative authority over teachers to monitor, observe, evaluate and provide feedback on classroom teaching. It is the policy of the Ministry of Education $(2001 ; 2002)$ that heads of department and head teachers should carry out supervision of teachers to provide advisory services. However, the study revealed that teachers viewed lesson supervision as fault finding. At one of the schools, the head of department reported that he faced resistance from the teachers when he attempted to observe lessons to provide professional advice. At another school, the head teacher reported that the teacher of SDS refused to be supervised by the head of department because he claimed to be more knowledgeable in the subject than the Head of Department who had never taught the subject.

Such resistance to supervision is a teacher factor which, according to the theoretical framework of this study as given in Figure 1, can hinder the effective implementation of SDS. Unless school-based supervision of teachers was institutionalised, the responsibility of supervising teachers would be left to school inspectors who rarely visited schools due to lack of adequate resources such as funding.

\section{Conclusion}

Based on the objectives and theoretical framework of the study, the results have shown that the implementation of SDS faced a lot of challenges that mainly resulted from poor planning. The implementation was poorly resourced in terms of trained teachers, teaching and learning resources, and inadequate funding of inspectors for curriculum implementation monitoring visits to schools. In addition, heads of department and head teachers were not given in-service training on school level supervision of curriculum implementation. It was therefore concluded that the implementation of the revised senior secondary school curriculum was poorly managed such that the schools did not have adequate capacity to successfully implement the teaching of newly introduced subjects like SDS. Consequently, the students' academic performance in national examinations was negatively impacted. These challenges further indicate that the introduction of new subjects in a school curriculum is a delicate and critical process that demands sufficient preparation and support to teachers from within and outside the school.

\section{Policy implications}

The findings of the study provide policy guidance for managing future curriculum implementations. The Ministry of Education should introduce a policy for ensuring that future curriculum review and implementation are adequately planned for in terms of availability of instructional materials, teacher training, and in-service training and orientation of teachers on content and pedagogical approaches.

At school level, there was almost zero supervision of teachers in their teaching of SDS by the heads of department and head teachers due to lack of supervision skills. Therefore there is need for a policy to ensure that heads of department and head teachers who supervise curriculum implementation in their respective schools are given orientation and in-service training on school level supervision and management of curriculum implementation. This entails that the Ministry of Education needs to come up with a policy on the Continued Professional Development (CPD) of teachers, heads of department and head teachers to ensure quality delivery of school curriculum.

\section{Suggestions for further research}


DOI: $10.21522 /$ TIJMG.2015.03.02.Art011

ISSN: $2520-310 \mathrm{X}$

The study investigated challenges faced by teachers, heads of department and head teachers in the implementation of SDS. To fully understand the underlying factors behind the students' low performance, future studies need to go beyond teachers' experiences and investigate learner factors.

\section{Acknowledgements}

I am very grateful to the South Eastern Education Division Office of the Ministry of Education for granting me permission to collect data from the schools and the Divisional Office. I also owe a lot of thanks to all the teachers, Heads of Department, Head teachers and the School Inspector who participated in the study. The study would not have been a success without their cooperation to provide information.

\section{References}

[1]. Aubusson, P.J. \& Watson, K. (1999). Issues and Problems Related to Science Curriculum Implementation in Pakistan: Perception of Three Pakistani Curriculum Managers. Science Education, 83, 603 - 620.

[2]. Bekoe, S.O. \& Eshun, I. (2013). Curriculum Feuding and Implementation Challenges: The Case of Senior High School (SHS) Social Studies in Ghana. Journal of Education and Practice, 4(5), 39 - 45.

[3]. Benavot, A. \& Resh, N. (2003). Educational Governance, School Autonomy, and Curriculum Implementation: A Comparative Study of Arab and Jewish Schools in Israel. Journal of Curriculum Studies, 35(2), 171 - 196.

[4]. Bennett, S.N., Wragg, E.C., Carre, C.G \& Carter, D.S.G (1992). A Longitudinal Study of Primary Teachers' Perceived Competence, and Concerns about, National Curriculum Implementation. Research Papers in education Policy and Practice, 7 (1), $53-78$.

[5]. Bennie, K. \& Newstead, K. (1999). Obstacles to Implementing a New Curriculum. In M.J. Smith \&A.S. Jordaan (Eds.), Proceedings of the National Subject Didactics Symposium (pp 150 - 157). Stellenbosch: University of Stellenbosch. Retrieved on July 25, 2005 from http://academic.sum.ac.za/mathed/MALATI/Files/Statistics99.pdf.

[6]. Chakwera, E.W.J. (2005). Improving Examination Performance through Teacher Capacity Building in Assessment. A Paper presented at the 3rd Sub-Regional Conference on Assessment at Sun ' $n$ ' Sand Hotel, Mangochi, Malawi from 30th May to 3rd June 2005.

[7]. Dzimiri, W. \& Marimo, S.T. (2015Challenges faced in the implementation of the Zimbabwe Localised Advanced Level Geography Syllabus: A Case of Gweru District High Schools. Global Journal of Interdisciplinary Social Sciences, 4(2), 52-56

[8]. Fraser-Thomas, J.L. \& Beaudoin, C. (2002). Implementing a Physical Education Curriculum: Two Teachers Experiences. Canadian Journal of Education, 27 (2), $249-268$.

[9]. Fullan, M. (2001). The New Meaning of Educational Change (3rd Ed). New York: Teachers College Press.

[10]. Glatthorn, A. A. (1994). Developing a Quality Curriculum. Virginia: Association for Supervision and Curriculum Development.

[11]. Glickman, C.D. (1990). Supervision of Instruction: A Developmental Approach (2 ${ }^{\text {nd }}$ Ed.). Boston: Allyn and Bacon.

[12]. Government of Malawi (2002). Malawi Poverty Reduction Strategy Paper: Final Draft. Ministry of Finance \& Economic Planning, Lilongwe, Malawi.

[13]. Graham-Jolly (2003). The Nature of Curriculum Change Management. In Coleman, M. Graham-Jolly \& Middlewood, D. (Eds). Managing the Curriculum in South African Schools. London: Commonwealth Secretariat.

[14]. Hart, A.W. (1994). Work Feature Values of Today's and Tomorrow's Teachers: Work Redesign as an Incentive and School Improvement Policy. Educational Evaluation and Policy Analysis, 16 (4), 458 - 473.

[15]. Jansen, J. (2003) On the Politics of Policy: State and Curriculum after Apartheid. In Coleman, M. GrahamJolly \& Middlewood, D. (eds). Managing the Curriculum in South African Schools. London: Commonwealth Secretariat. 
[16]. Jones, A., Harlow, A. \& Cowie, B. (2004). New Zealand Teachers' Experiences in Implementing the Technology Curriculum. International Journal of Technology and Design Education. 14, 102 - 119.

[17]. Kurasha, P. \& Chabaya, A. R. (2013). Curriculum development and implementation: factors contributing towards curriculum development in Zimbabwe higher education system. European Social Sciences Research Journal, 1(1), 55-65.

[18]. Kuthemba Mwale, J.B. (2000). Presidential Committee on the Quality of Education in Malawi: Final Report. Zomba.

[19]. Little, J.W. (1993). Teachers' Professional Development in a Climate of Educational Reform. Educational Evaluation and Policy Analysis, 15 (2), 129 - 151.

[20]. Lockheed, M.E., Vail, S.C. \& Fuller, B. (1986). How Textbooks Affect Achievement in Developing Countries: Evidence from Thailand. Educational Evaluation and Policy Analysis, 8 (2), 379 - 392.

[21]. Makunja, G. (2016). Challenges Facing Teachers in Implementing Competence-Based Curriculum in Tanzania: The Case of Community Secondary Schools in Morogoro Municipality. International Journal of Education and Social Science, 3(5), 30-37.

[22]. Medrano, H. \& Curts, J. (2004). Alignment of State Standards and Teacher Preparation Program Standards. In National Evaluation Systems (eds). What is a Qualified, Capable Teacher? Massachusetts: National Evaluation Systems.

[23]. Middleton, S. (1999). Between a Rock and Shifting Sands: Issues of Curriculum implementation in Secondary Schools. A Paper presented at the telecom Technology Education Conference, Kings College, Auckland, New Zealand, 16 April 1999.

[24]. Ministry of Education (1982). Handbook for Inspectors. Lilongwe, Malawi.

[25]. Ministry of Education (2000). Training Manual for Teachers: New Junior Secondary School Curriculum. Domasi: Malawi Institute of Education.

[26]. Ministry of Education (2001). Policy \& Investment Framework. Lilongwe, Malawi.

[27]. Ministry of Education (2002). Vacancy: Head of Department II (P7). Circular Ref. No. TSC /VAC/5/2002 of $4^{\text {th }}$ November 2002. Lilongwe: Malawi Teaching Service Commission.

[28]. Mtetwa, A.C. (2003). Has It Happened in Mpumalanga? An Evaluation of the Implementation of Curriculum 2005. M.A. Thesis, University of Pretoria

[29]. Ndawi, O.P. (1994). Implementing Curriculum Innovation at the Operational (School) Level. In Malawi Institute of Education, Curriculum Development, Implementation and Evaluation: Sub Regional Workshop Report.

[30]. Njoku, N.C \& D.I. Njoku (2015). Challenges to Effective Implementation of Christian Religious Studies Curriculum: A Study of Secondary School Pupils in Ebonyi State of Nigeria. Journal of Education and Practice, 6(18), 176-180.

[31]. Nyirenda, D.M.C. (1994). An Evaluation of the implementation of the National Curriculum Changes in Science and Mathematics in Malawi with reference to parallel changes in England and Wales. A Doctoral Thesis. University of Nottingham.

[32]. Nyirenda, D.M.C. (2005). Malawi Secondary School Curriculum Reform: Issues and Challenges. A paper presented at the National Education Conference, March 29 to April 1, 2005.

[33]. Ogar, O.E. \& Aniefiok, E.A. (2012). The Challenges of Curriculum Implementation in Nigeria Teacher Education. Journal of Education and Practice, 3(15), 127-131.

[34]. Okoth, T.A. (2016). Challenges of Implementing a Top-down Curriculum Innovation in English Language Teaching: Perspectives of Form III English Language Teachers in Kenya. Journal of Education and Practice, 7(3), 169177.

[35]. Ongachi, W.M., Okello, O.M. \& James, A. (2013). Challenges on Implementation of Art and Design Curriculum in Secondary Schools in Kenya. Academic Research International, 4(5), 390-397.

[36]. Posner, G.J (1995). Analyzing the Curriculum (2nd ed.). New York: McGraw-Hill.

[37]. Raudenbush, S.W., Eamsukkawat, S., Di-Ibor, I., Kamali, M. \& Taoklam, W. (1993). On-the-Job improvements in Teacher Competence: Policy Options and Their Effects on Teaching and learning in Thailand. Educational Evaluation and Policy Analysis, 15(3), 179 - 297. 
DOI: $10.21522 /$ TIJMG.2015.03.02.Art011

ISSN: $2520-310 \mathrm{X}$

[38]. Rogan, J \& Aldous, C. (2005). Relationships between the Constructs of a Theory of Curriculum Implementation. Journal of Research in Science Teaching, 42 (3), 313 - 336.

[39]. Rogan, J.M. \& Grayson, D. J. (2003). Towards a Theory of Curriculum Implementation with particular reference to Science Education in Developing Countries. International Journal of Science Education, 25 (10), $1171-1204$.

[40]. Shilling, T. (2013). Opportunities and Challenges of Curriculum Mapping Implementation in One School Setting: Considerations for School Leaders. Journal of Curriculum and Instruction, 7(2), 20-37.

[41]. Syomwene, A. (2013). Factors Affecting Teachers' Implementation of Curriculum Reforms and Educational Policies in Schools: The Kenyan Experience. Journal of Education and Practice, 4(22), 80 - 86.

[42]. Urbanski, A. (2004). Teachers' Use of Data to Improve Students Learning. In National Evaluation Systems (eds). What is a Qualified, Capable Teacher? Massachusetts: National Evaluation Systems.

[43]. Van Driel, J.H., Beijaard, D. \& Verloop, N. (2001). Professional Development and Reform in Science Education: The Role of Teachers' Practical Knowledge. Journal of Research in Science Teaching, Vol. 38 (2) pp. 137 - 158.

[44]. Wallace, J. \& Louden, W. (1992). Science Teaching and Teachers' Knowledge: Prospects for Reform of Elementary Classrooms. Science Education, 76, 507 - 521.

[45]. Zanzali, N.A.A (2003). Implementing the Intended Mathematics Curriculum: Teacher Beliefs about the Meaning and Relevance of Problem Solving. The Mathematics Education into the $21^{\text {st }}$ Century Project. Proceedings of the International Conference: The Decidable and Undecidable in Mathematics Education, Brno, Czech Republic, September 2003. 